\title{
Online Course Construction and Application of Intelligent Control Major Practical Teaching in Higher Vocational Education Based on Virtual Simulation
}

\author{
Fei You
}

\author{
Institute of Artificial Intelligence, Chongqing Real Estate College, Chongqing, China \\ 178846102@qq.com
}

\begin{abstract} and network teaching.

\section{Problem Analysis and Research Basis}

\subsection{Research status at home and abroad}

With the rapid development of computer technology and Internet, online teaching as a traditional form of classroom teaching has made rapid development. At present, the online teaching of theory course has been quite mature, but as another important content of students' learning experiment course, because of the limitation of time and space, there are huge obstacles in the development of online teaching. Therefore, virtual simulation experiment is applied to practical teaching [1], and the inherent accuracy, effectiveness, vividness and shape of virtual simulation experiment are used. It is very significant to promote the development of online teaching of experimental courses to realize online teaching with the characteristics of image.

With the rapid development of virtual simulation technology, it has gradually penetrated into the field of education. Many famous universities also develop and design virtual simulation experiments. Compared with foreign countries, although the development time of virtual simulation experiment technology in China is relatively short, the universities and scientific research institutions in China have also actively invested in this field.
\end{abstract}

The purpose of this research is to apply virtual simulation experiment to practice teaching through the construction of practice teaching online course based on virtual simulation, more systematically plan and build online practice teaching resources of intelligent control specialty in higher vocational education, and gradually form a mutual supporting education and teaching system of classroom teaching, practical teaching

Keywords: Virtual simulation experiment, Practical teaching, Online course

\subsection{Existing problems}

\subsubsection{Experimental teaching is limited by space}

In the traditional experimental teaching, as the lack of experimental teaching instruments and equipment, students are limited to participate in the development and independent operation of the experiment. Students are not the main body of the whole experimental process in the experimental course learning, but only stay in the simple imitation according to the demonstration and explanation of teachers, the operation steps on the experimental handout, and the students' practical ability and innovative thinking dimension ability has not been effectively trained and cultivated. In addition, due to the limitation of time and space, the experimental teaching mode is relatively single and fixed.

\subsubsection{Online teaching lacks experimental teaching resources}

At present, the online teaching of the theory course has been quite mature. The students participating in the online teaching can learn online by downloading teaching courseware, teaching video, teaching materials, or online on demand. But for experimental courses, due to the limitation of time and space, it seems to be the "breakpoint" [1] of online teaching. Some researchers hope to solve this problem by transmitting some pictures and experimental data of experimental phenomena through the network, but this is not the real online teaching of experimental courses. Therefore, it is significant to apply virtual simulation experiment to practical teaching [4] and realize online education.

At present, there are the following problems in practice teaching in the College of artificial intelligence of our university:

1)Experimental teaching instruments and equipment are insufficient to meet the needs of each student to participate in the experiment.

2)For some abstract circuit experiments and equipment operation principle experiments, the teaching effect is not 
obvious only by the teacher's explanation and demonstration.

3)For some lossy equipment, maintenance is often needed, and the damage rate is high, which affects the experiment. 4)Experimental courses are limited by time and space, so students can't practice after class.

5)During the novel coronavirus pneumonia outbreak, our school adopted the way of "non-stop teaching, non-stop learning" to conduct online teaching and learning, many practical courses cannot meet the online teaching.

\subsection{Research basis}

At present, the use of computer in teaching is very common. People have a correct understanding and proper use of computer as a teaching aid. The popularization of the Internet in our life helps people to acquire knowledge and information by using the Internet consciously and conveniently. In addition, the advanced digital technology can easily convert the analog signals in the traditional instruments into digital signals, which makes the computer processing and network transmission of experimental data possible, and provides the basic conditions for the realization of virtual experiment. In addition, there are also the needs of national teaching reform curriculum construction and school practice online curriculum construction, as well as the software and hardware conditions of developing practice online curriculum and the teacher team of developing practice Virtual Simulation online teaching.

\section{Solutions and Objectives}

\subsection{Research objectives}

The purpose of this project is to plan and build online practical teaching resources more systematically through the construction of online practical teaching courses based on virtual simulation, and gradually form a mutual supporting education and teaching system of classroom teaching, practical teaching and online teaching.

\subsubsection{The virtual simulation technology will be integrated into the practice course to improve the connotation of intelligent control experiment project.}

As a science and engineering discipline with strong practicality, intelligent control specialty can keep up with the development trend of science and technology by using virtual simulation technology. It integrates cutting-edge technology into teaching through innovative activities such as subject research, technology development, engineering experiment, achievement transformation, industrialization, etc., so as to realize scientific research activities and teaching activities, scientific and technological innovation and personnel training perfect combination [9].

\subsubsection{Develop the practice course project based on virtual simulation, enrich the teaching methods, and promote the enthusiasm and initiative of students' independent learning.}

The intelligent control major in our university involves a large number of subject knowledge and equipment working principle courses. It is difficult for students to fully understand the relatively abstract knowledge only by simple classroom explanation or plane multimedia assisted teaching. Through the virtual simulation technology, the subject knowledge is presented in front of the students directly, so that students can see the knowledge in the virtual scene close to the real environment Visual presentation will greatly mobilize students' enthusiasm and initiative in learning, and get twice the result with half the effort. Through the development of simulation experiments, students can have a deeper understanding of the experimental mechanism, reaction law and experimental phenomenon of the experimental items that are difficult to carry out real experiments, which is helpful for them to understand and master the subject knowledge more comprehensively, and provides a feasible way for students to change from passive learning to active learning.

\subsubsection{Combining the practice course based on virtual simulation with the theory course organically, a complete online resource of intelligent control course is formed.}

Build online courses, systematically plan and build online practical teaching resources, and gradually form a mutual supporting education and teaching system of classroom teaching, practical teaching and online teaching.

\subsection{Research contents}

\subsubsection{The development of practical teaching project of intelligent control specialty in Higher Vocational Education Based on virtual simulation.}

The aim of higher vocational schools is to cultivate professional and technical talents. In teaching, it pays attention to the cultivation of students' practical ability and professional skills. It is conducive to optimize the practical teaching system, highlight the characteristics of vocational colleges, and constantly deepen the teaching reform. This project aims at the problems existing in the practice teaching of AI college at present. Based on the platform 
course of intelligent control specialty group, it develops the practice teaching project based on virtual simulation.

\subsubsection{Based on virtual simulation, the construction of practice course of intelligent control specialty in higher vocational education.}

\subsubsection{The combination of hardware and software technology is adopted.}

The application of software technology is the great advantage of virtual simulation experiment course, which is also the technical characteristic of virtual experiment different from traditional experiment. In the virtual experiment system, the combination of software and hardware [5] is used to control the experiment operation, and the modular and hierarchical design idea is realized by the way of complementary advantages of software and hardware.

Figure 1 shows the hierarchical design of virtual simulation experiment system.

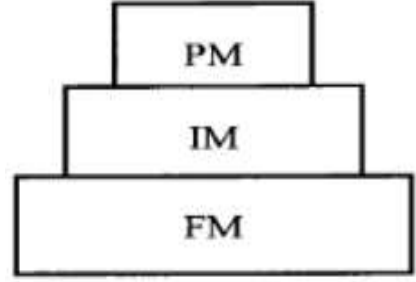

Figure 1 Hierarchical design of virtual simulation experiment system

Among them, PM represents the highest level of experimental project module, IM represents the middle level of virtual instrument module, FM represents the lowest level of software function module in the system. The modules of each level have not only hierarchical subordination, but also belong to different levels of separation.

\subsubsection{Virtual instrument technology is the core technology.}

Virtual instrument $[1,2,7]$ is a revolutionary new technology which combines traditional instrument technology with computer technology and software technology. Virtual instrument is more general than traditional electronic instrument. It is more flexible and economical in building and changing the function and technical performance of the instrument. It can adapt to the requirements of the rapid development of modern science and technology for the renewal and expansion of the function and performance of the experimental instrument. It has a good development prospect.

\subsubsection{It is advanced and accurate based on computer technology.}

Computer is the representative of the advanced nature of modern science and technology. In the construction of virtual simulation experiment course, first of all, we make full use of the excellent application characteristics of computer to help improve the overall performance of the system. Secondly, it combines the rapid development of software technology with the hardware advantages of traditional experimental instruments, takes hardware as the basis of the system, and uses software to build and form the overall structure of the system. Finally, the application mode of the system is extended and extended to the extent of asynchronous in different places by using the increasingly developed network technology and the Internet as the network platform of the system [6].

\subsubsection{Cloud data reference.}

\subsubsection{Online course construction.}

The virtual simulation experiment course or teaching resources will be constructed, based on the network, and through the network platform, the virtual simulation experiment online course will be carried out in combination with the real and the virtual, so as to realize the sharing of experiment resources.

\subsection{Solutions to problems}

\subsubsection{Literature retrieval.}

In the analysis of the development of virtual experiments at home and abroad, the literature retrieval method [2] is used.

\subsubsection{Comparative study.}

Using the method of comparative study [2], this paper compares the virtual simulation experiment with the traditional experiment, summarizes and analyzes the advantages and disadvantages of the virtual simulation experiment, so as to provide targeted measures to overcome the shortcomings of the virtual experiment.

\subsubsection{System research method.}

In the part of teaching design of virtual simulation experiment, the system research method is adopted. 


\section{Innovation Points}

The project adheres to student-oriented, makes full use of the Internet and virtual simulation technology to realize the diversity of teaching methods, mainly reflected in:

1)The abstract experimental process is concentrated in the vivid animation demonstration, which greatly improves the teaching effect.

2)The process teaching based on the quality of experimental teaching has been practiced.

3)It breaks through the time and space limitation of teaching and learning, and strengthens students' independent learning.

4)The investment of laboratory construction is saved and the cost of experiment teaching is reduced.

5)School enterprise cooperation, jointly develop virtual simulation experiment courses, realize complementary advantages, and cultivate technical and skilled talents.

6)In order to promote the development of online education, the teaching resources of virtual simulation experiment are used to construct online courses [3].

\section{Conclusion}

1)Through the construction of the practice course of intelligent control specialty based on virtual simulation, the experimental teaching course system of this specialty is formed.

2)Virtual experiment environment, experiment object and high simulation instrument model [8] are helpful for students to understand abstract principle and knowledge intuitively and vividly, and can greatly enrich and expand traditional experiment practice content and training mode.

3)Through the "Internet, virtual reality" which is more popular with young people, it can promote the opening of "students' independent experiment". Compared with the traditional experiment teaching, the virtual simulation experiment project can further strengthen the cultivation of students' innovative practice ability.

4)Virtual simulation experiment teaching can further promote the deep integration of production, learning and research, and expand and deepen the space of practice teaching of intelligent control specialty.

5)Under the mode of virtual simulation experiment teaching, we can combine many kinds of information resources of intelligent control specialty closely, form cooperative advantages from many angles and all directions, and promote them to the majority of higher vocational colleges, enterprises and training institutions based on the network, which is also impossible for traditional experiment teaching.

\section{ACKNOWLEDGMENT}

This research was supported by Chongqing Real Estate College.

\section{REFERENCES}

[1] Zhu min. Research on virtual experiment and teaching application - Taking Physical Experiment Teaching of University as an example. 2006 doctoral dissertation of East China Normal University,pp.2.

[2] Bai Juan. Virtual experiment teaching and design research. Master's thesis of Shaanxi Normal University in 2005,pp.4-5, 26.

[3] Wang Guanhu. On the application of virtual reality technology in Distance Education [J]. Symposium on information technology and virtual reality application. Nankai University Press 2007.9, pp.86-89.

[4] Yin Wuliang.New Developments in teaching Electromagnetics through Advanced Numerical simulations and Virtual Experiments.Creative Education.2018.

[5] Zong Bangfeng.Application of virtual simulation technology in electronic technology experiment teaching in Colleges and Universities [J]. Journal of Shanxi energy University.2020.

[6] Shan Meixian, Li Yi. Virtual experiment principle and teaching application $[\mathrm{M}]$. Beijing: Education Science Press.2005.

[7] Berlin. Research on core technologies and typical cases of networked virtual instruments. 2004 Ph.D. dissertation, Chongqing University.

[8] Zhou Chaohui. Research and practice of virtual experiment system $[\mathrm{J}]$. China Science and technology information.2005.15, pp.4.

[9] Li Danting, Lan Shuang, Ma Lixin, Yu Guiwen, Gong Yunqi. Research on the construction of virtual simulation experiment teaching system [J]. Contemporary education practice and teaching research.2020. 